\title{
Etiloxidação: se bebi, quando poderei dirigir com segurança?
}

\author{
Alcohol oxidation: if I have drunk, when will it be safe to drive?
}

\author{
Cássio Mattos Honorato
}

Honorato CM. Etiloxidação: se bebi, quando poderei dirigir com segurança? Saúde, Ética \& Justiça. 2013;18(1):88-102.

RESUMO: O Trânsito Seguro constitui direito fundamental e, principalmente, dever de todos os participantes do fenômeno trânsito. Cada cidadão, como corresponsável pela segurança dos demais, precisa conhecer os efeitos que as bebidas alcoólicas exercem no organismo humano e respeitar o período de vedação imposto a todo aquele que ingeriu bebida e, após a fase de desintoxicação etílica, pretende conduzir veículo sem violar as normas de segurança, sabendo que a taxa de álcool no sangue (TAS) encontra-se em zero. A presente pesquisa buscou estabelecer o tempo necessário para que uma pessoa, que ingeriu determinada quantidade de bebida alcoólica, possa realizar a etiloxidação e, somente então, dirigir veículo com segurança nas vias terrestres.

DESCRITORES: Direitos humanos; Consumo de bebidas alcóolicas/legislação \& jurisprudência; Bebidas alcóolicas/ toxicidade; Intoxicação alcoólica/complicações; Condução de veículo/legislação \& controle; Acidentes de trânsito/ prevenção \& controle.

\footnotetext{
Mestre em Direito pela Universidade Estadual do Paraná - UNESPAR, campus Jacarezinho. Especialista em Trânsito pela Polícia Rodoviária do Estado de São Paulo. Promotor de Justiça no Estado do Paraná. Endereço para correspondência: Av. São José, n. 752. Ap. 2002. Bairro Cristo Rei. Curitiba, PR. CEP: 80.050-350. E-mail: cmhonorato@mp.pr.gov.br
} 


\section{INTRODUÇÃO}

$\mathbf{M}$ uito curiosas são as coisas que ocorrem (e, por vezes, como essas coisas ocorrem) em nossas vidas; especialmente como as pessoas nos surpreendem com sua sabedoria.

Há alguns dias, minha mãe (administradora do lar, há mais de 40 anos, e credora de nosso sucesso pessoal e profissional) expôs uma situação aparentemente simples e promoveu o questionamento bombástico: "Filho, ontem à noite, durante $\mathrm{o}$ jantar, bebi dois cálices de vinho tinto. Hoje, domingo de manhã, já posso dirigir?".

Pensemos, por alguns instantes, na complexidade da pergunta:

$\left(1^{\circ}\right)$ Ela sabe que beber e dirigir é errado. Provavelmente não saberia identificar as normas jurídicas que tratam do tema, mas conhece muito bem o dito popular: "Se beber, não dirija!".

$\left(2^{\circ}\right)$ A ingestão da bebida (i.e., vinho) ocorreu na noite anterior. Após uma noite de sono, o corpo de uma pessoa do sexo feminino, com aproximadamente 60 quilos, já teria convertido (ou oxidado) o álcool ingerido na noite anterior, ou (na hipótese de assumir a direção de veículo automotor) ainda estaria dirigindo sob influência de álcool e, desse modo, realizando infração gravíssima e crime de trânsito?

$\left(3^{\circ}\right)$ Nesse contexto emerge o segundo questionamento: "Se bebi, quando poderei dirigir com segurança?", fazendo-se necessário determinar a partir de que momento a pessoa que ingeriu bebida alcoólica poderá conduzir veículo automotor sem cometer infração administrativa de trânsito, sem realizar um ilícito penal e sem colocar em risco os demais participantes do fenômeno trânsito ${ }^{(1)}$

Para responder a essa pergunta que, ao início, parecia tão singela, foi necessário recorrer às consagradas obras de Widmark ${ }^{2}$, Simonin ${ }^{3}$, Arbenz ${ }^{4}$ e França ${ }^{5}$, buscando princípios e fenômenos relacionados à ingestão de bebidas alcoólicas, em especial para compreender o comportamento do álcool no corpo humano e identificar fórmulas capazes de determinar a quantidade de álcool ingerida (em dois cálices de vinho), a taxa de álcool no sangue (TAS) e o coeficiente de oxidação (i.e., metabolismo ou conversão) do álcool pelo organismo humano.

Os estudos de Widmark ${ }^{2}$ permitem determinar a quantidade de álcool no sangue $(c)$ por meio de cálculos matemáticos fundados em três informações essenciais: a quantidade de álcool ingerida $(A)$, o peso corporal $(p)$ e o quociente de redução $(r)$, que representa a relação de distribuição do álcool entre o sangue e o restante do corpo, de modo que $A=p$.r.c.

Em complemento, Simonin ${ }^{3}$ adverte para os cálculos necessários à transformação de $c$ (quantidade de álcool no sangue, expressa em g/kg) em Taxa de Álcool no Sangue (TAS, expressa em g/L) e Arbenz ${ }^{4}$ identifica o coeficiente de etiloxidação, permitindo que seja atualizada a TAS no momento do fato (ou seja, enquanto dirigia veículo automotor sob influência de álcool) e não apenas no momento da coleta da amostra; bem como (e aqui se encontra a chave para responder à pergunta realizada por minha mãe) o período necessário (ora denominado período de vedação) para que o organismo converta o álcool ingerido e promova a desintoxicação etílica.

\section{O COMPORTAMENTO DO ÁLCOOL NO CORPO HUMANO}

As pesquisas realizadas por Widmark $^{2}$ contemplam informações indispensáveis à compreensão da fisiologia do consumo do álcool e revelam algumas curiosidades que merecem expressa menção: (i) a rápida absorção do álcool pelo organismo, influenciando desde logo o cérebro; (ii) a necessidade de aguardar o equilíbrio de difusão (entre o álcool no sangue e o álcool distribuído para as células) para a coleta do material a ser submetido a exame de alcoolemia; (iii) a existência de uma razão constante entre a TAS e a concentração de álcool no ar alveolar; (iv) leis da cinética que demonstram o fato de o fator $\beta$ de conversão (do álcool no organismo) independer da quantidade ingerida e realizar-se de forma linear; bem como, (v) o fato de o consumo de álcool durante a gestação afetar as células do embrião na mesma proporção que o organismo materno, chegando a falar-se em alcoolismo congênito.

\section{A RÁPIDA ABSORÇÃO PELO ORGANISMO}

A intoxicação alcoólica apresenta quatro distintas fases: ingestão, absorção (para a corrente sanguínea), distribuição (ou difusão) e, por fim, a fase de defesa do organismo, consistente em eliminação e etiloxidação ${ }^{4}$.

Segundo Widmark ${ }^{2}$, uma das propriedades fundamentais do álcool consiste na habilidade de penetrar rapidamente nas células. Pesquisas revelaram que a absorção pelo organismo é extremamente rápida, iniciando seu percurso desde o estômago até a corrente sanguínea, e desta até as demais células, em apenas um minuto.

A velocidade de absorção depende de vários fatores ${ }^{4}$, porém os autores confirmam que a passagem

\footnotetext{
(1) O termo participantes do trânsito é sabiamente empregado por Albrecht ${ }^{1}$ em substituição à expressão usuários da via terrestre.
} 
da fase de absorção para a difusão é muito rápida, de modo que "El veneno pasa rápidamente del estómago a la sangre por simples mecanismo de difusión (Nicloux) y después se reparte por todo el organismo"33 (p.568).

Iniciada a fase de absorção, a média das amostras pesquisadas por Widmark ${ }^{2}$ necessitou de (apenas) mais 08 a 10 minutos para promover a distribuição do álcool pelo organismo em busca do ponto de equilíbrio (ou equilíbrio de difusão). Essas pesquisas também revelaram que as primeiras fases da intoxicação alcoólica normalmente completam-se em até uma hora após a ingestão da bebida. Outros autores, como Sadler ${ }^{6}$, por exemplo, sustentam que a absorção pode ocorrer em até três horas.

\section{A VELOCIDADE DE ABSORÇÃO PREOCUPA $O$ SÁBIO, DESDE O SÉC. XIII}

Não obstante a nobre origem da palavra whisky (do gálico usquebaugh, que significa água da vida), tampouco o fato de, na Idade Média, ter sido “considerado como um remédio para aliviar os males, pois dissipava as preocupações mais rapidamente do que o vinho e a cerveja, produzindo um alívio mais eficiente contra a dor", a verdade é que o álcool é responsável direto por grande parcela dos eventos (culposos ou dolosos) de trânsito ${ }^{7}$ e atua como "poderoso factor criminógeno"3 (p.564), exercendo grande influência sobre a criminalidade.

Os problemas sociais decorrentes do consumo de bebidas alcoólicas antecedem o surgimento dos veículos automotores e preocupam, há séculos, as autoridades públicas. Exemplo interessante encontra-se na Espanha, no Século XIII, em que o Rei Alfonso X, conhecido como El Sabio ${ }^{(2)}$, impôs uma lei determinando que, junto a cada jarra de vinho, os taberneiros deveriam servir um complemento comestível, para que o bebedor não recebesse aquele líquido (impregnado de álcool) com o estômago vazio e, como consequência, não se embriagasse facilmente. Esse acompanhamento do vinho consistia, geralmente, em uma generosa fatia de presunto, que era servida e colocada sobre a boca da jarra ou garrafa, como uma tampa (ou melhor, "tapándola" em castelhano $^{9}$, p.139), dando origem às Tapas Españolas ${ }^{(3)}$.

Essa percepção local foi ampliada, ao longo dos anos, alcançando o nível internacional em 2004 (já no presente Século XXI), quando as Nações Unidas reconheceram a existência de uma grave crise mundial de segurança viária (verdadeira epidemia, e grave problema de saúde pública, aferida pela Organização Mundial de
Saúde (OMS), por meio da Resolução A/57/309 e do Informe $\mathrm{A} / 58 / 228$, de 2003).

Como bem observou Lemes apud Hoffmann et al. ${ }^{11}$ (p.137), "Em trânsito, a rapidez com que você passa da saúde para a doença é, talvez, mais rápida e imprevisível do que em todas as outras circunstâncias de risco que a vida cotidiana oferece". De fato, basta um segundo de negligência ou a violação de uma norma de cuidado para que uma pessoa sadia, em plena capacidade produtiva, integre as estatísticas de mortes e lesões no trânsito.

Segurança Viária, portanto, constitui um grave problema de saúde pública, que passou (em abril de 2004) a ser coordenado em nível mundial pela $\mathrm{OMS}^{(4)}$.

Identificado o problema, cabe a todos (e a cada um de nós) reconhecer e cumprir seu papel para a realização da Segurança Viária como direito fundamental de segunda dimensão; ou seja, dever do Estado e responsabilidade de todos os participantes do fenômeno trânsito.

\section{A INFLUÊNCIA DO ÁLCOOL E EFEITOS SOBRE O CÉREBRO: HÁ LIMITE SEGURO?}

Retornando à face científica do tema, os estudos de Widmark ${ }^{2}$ também revelam que, durante a fase de absorção (e mesmo antes de atingir o ponto de equilíbrio), o cérebro é dos órgãos mais afetados, pois recebe rapidamente uma grande concentração de álcool por se tratar de uma das áreas mais vascularizadas do corpo humano. Essa rápida e desproporcional concentração de álcool no cérebro perdura até que, por meio da difusão, o álcool seja distribuído para o restante do corpo.

A preocupação do sábio Rei de Espanha e das Nações Unidas é válida, pois os efeitos do álcool sobre o cérebro (além de influenciar muito rapidamente os sentidos) produzem distorção na valoração e na percepção de risco, o que, de acordo com Rozestraten apud Biancchi ${ }^{13}$, altera a análise de situação e influencia a tomada de importantes decisões no trânsito.

Nesse sentido, destaca-se a exposição de Hoffmann $^{11}$ :

\footnotetext{
“Os perigos do álcool ao volante são bastante evidentes na dimensão psíquica, pois o condutor que dirige alcoolizado geralmente infravalora os efeitos do mesmo sobre sua capacidade de rendimento; o álcool produz nele um sentimento subjetivo de acreditar que possui melhor capacidade para dirigir; aparece uma falsa segurança em si mesmo, que o faz aumentar a tolerância
}

\footnotetext{
${ }^{(2)}$ Há divergências em relação à origem dessa legislação em Espanha. Alguns historiadores atribuem a recomendação à Rainha Isabel, $a$ Católica.

(3)“Tapa. [...]. Alimento ligero que se sirve como acompañamiento de una bebida"10.

(4) $\mathrm{O}$ convite foi realizado pela ONU por meio da Res. A/RES/58/289, em 14.04.2004 (item 2). O aceite da OMS foi consignado na Res. WHA57.10, durante reunião plenária de 22.05.2004.
} 
ao risco, levando-o a tomar decisões mais perigosas do que os habituais. As bebidas alcoólicas incrementam, também, as condutas impulsivas e agressivas, ao mesmo tempo em que diminuem a responsabilidade, dando lugar a um considerável aumento das infrações [...]." (p.384)

Fácil perceber as graves consequências do álcool no organismo daquele que conduz veículo automotor e necessita, em curto intervalo de tempo, reconhecer situações de risco e tomar decisões complexas para manter o trânsito em condições seguras.

Muito se pergunta a respeito de quantidades isentas ou faixas de tolerância (a serem consideradas pela legislação), ou seja, níveis em que, apesar de haver ingerido bebida alcoólica, uma pessoa poderia conduzir veículo automotor sem prejuízo à segurança viária. Daí a pergunta: há níveis seguros de embriaguez ao volante?

Alguns autores, ao tratar da avaliação da taxa de álcool no sangue (i.e., alcoometria), consideram a escala de embriaguez a partir de $0,5 \mathrm{~g} / \mathrm{L}^{5,14}$; outros, de $0,75 \mathrm{~g} /$ $\mathrm{L}^{4}$. Para Simonin ${ }^{3}$, concentrações inferiores a $0,37 \mathrm{~g} / \mathrm{L}$ constituem intoxicação não aparente, porém adverte expressamente que:

"la cantidad de alcohol en sangre no tiene más que un valor indicativo; no es más que un elemento de diagnóstico médico-legal, el cual debe tener en cuenta los datos de información y las indicaciones siguientes: - alcoholemia inferior a 0,5c.c. por 1.000 (o 0,37g): intoxicación inaparente. - alcoholemia comprendida entre 0,5 y 2c.c. por 1.000 (o 0,37 y 1,5g.): presunción de trastornos tóxicos más o menos graves. - alcoholemia superior a 2c.c. por 1.000 (o 1,5g.): borrachera en la mayoría de casos" (p.588)

O Relatório Global sobre Segurança Viária ${ }^{15}$ divulgado pela OMS (em 2009) sustenta que "o risco de envolver-se em uma colisão aumenta significativamente quando a concentração de álcool no sangue (TAS) supera $4 \mathrm{dg} / \mathrm{L} "(\mathrm{p} .21)$.

A verdade é que o álcool influencia os sentidos, altera a percepção de risco e acarreta, sem dúvida alguma, prejuízo à segurança viária em qualquer nível. "Estudos indicam que com $0,2 \mathrm{~g} / \mathrm{L}$ o condutor já tem alterações detectáveis em testes de atenção dividida, funções visuais e acompanhamento de pontos em movimento"16 (p.166). Não há limite seguro para a embriaguez ao volante, daí o adágio: "Se beber, não dirija!".

Desse modo, não deveria falar-se em faixa de tolerância, muito menos estabelecer limites aceitáveis para um fator de risco à Segurança Viária, que aumenta a quantidade e agrava (e muito) as consequências dos eventos de trânsito. É notória a afirmação que "perto de $50 \%$ de acidentes fatais estão relacionados com o álcool" ${ }^{\prime 17}$ (p.140). Nesse sentido, aliás, destaca-se a crítica promovida por Wilde ${ }^{18}$ :

[...], quanto maior a TAS, maior a probabilidade de acidentes no trânsito - e não existe um nível crítico de TAS no qual as possibilidades aumentam de repente, como a lei no seu país pode sugerir. Enquanto você permanece abaixo do limite legal, suas probabilidades de ser multado por dirigir depois de beber serão muito reduzidas, mas mesmo abaixo desse limite, as probabilidades de ser envolvido num acidente crescem com a quantidade de álcool consumido. Em resumo, não existe uma TAS segura (p.180).

Não havendo uma margem segura (acima de zero), a previsão legislativa de faixas de tolerância constitui mecanismo de política criminal ou de compromisso político ${ }^{18}$ com a segurança viária. O cidadão de bem, consciente de sua responsabilidade social, deve lembrar-se do dito popular (acima mencionado) e somente dirigir com a certeza de encontrar-se com alcoolemia zero.

\section{FAIXAS DE TOLERANNCIA ADMITIDAS PELA LEGISLAÇÃO BRASILEIRA}

A previsão de faixas de tolerância à ingestão de álcool por condutores de veículos automotores não é privilégio da legislação brasileira, sendo estabelecidas por muitos países ${ }^{15}$

No Brasil, há distinção entre as faixas de tolerância previstas na esfera administrativa (em que se encontram definidas as infrações de trânsito) e no Direito Criminal.

$\mathrm{Na}$ esfera administrativa, a infração de trânsito por “dirigir em estado de embriaguez" já se encontrava descrita no art. 127, item 55, do Decreto-Lei n. 2.994, de 28.01.1941 (que instituiu o $1^{\circ}$ Código Nacional de Trânsito). As primeiras margens de tolerância, no Brasil, foram fixadas em 8dg/L pelas Resoluções 413/69 e 476/74, do CONTRAN. A Res. $737 / 89$ previa a mesma faixa de tolerância $(8 \mathrm{dg} / \mathrm{L})$, fazendo incluir tão-somente a equivalência de resultados obtidos por meio de etilômetro ${ }^{19}$.

O Código de Trânsito Brasileiro (em sua redação original, promulgada em 23.09.1997) não previu faixa de tolerância para a esfera criminal (optando pela elementar conduzir sob influência, e deixando a cargo da doutrina a interpretação dessa expressão) ${ }^{(6)}$; porém incorporou a orientação médico-legal à esfera administrativa, estabelecendo (em seu artigo 165) que constitui infração

\footnotetext{
${ }^{(5)}$ As conversões realizadas por $\operatorname{Simonin}^{3}$ levam em consideração a densidade absoluta (d) ou massa especifica do álcool (em que d=m $\left.\div \mathrm{v}\right)$. Assim, a quantidade de 0,5 c.c. corresponde a $0,376 \mathrm{~g}$ de álcool [pois, $\mathrm{d}=\mathrm{m} \div \mathrm{v}$, em que $0,7529=\mathrm{m} \div 0,5 \mathrm{ou} \mathrm{m}=0,7529 \div 0,5$ ]; e 2 c.c. equivalem a $1,505 \mathrm{~g}$.).

(6) Em relação às distintas orientações doutrinárias sobre as elementares do tipo penal descrito no art. 306 do CTB (Crime de Embriaguez ao Volante), consultar Honorato ${ }^{20}$.
} 
gravíssima de trânsito "dirigir sob a influência de álcool, em nível superior a seis decigramas por litro de sangue, ou de qualquer substância entorpecente ou que determine dependência física ou psíquica". Assim, em 1998, a faixa de tolerância foi reduzida de $8 \mathrm{dg} / \mathrm{L}$ para $6 \mathrm{dg} / \mathrm{L}$.

Uma década de vigência do CTB revelou a necessidade de agravamento das normas administrativas e criminais relacionadas à embriaguez ao volante. Para tanto, foi publicada (em 20.06.2008) a Lei n. 11.705 (conhecida como Lei Seca), "com a finalidade de estabelecer alcoolemia 0 (zero) e de impor penalidades mais severas para o condutor que dirigir sob a influência do álcool" (art. $1^{\circ}$ ). Alteradas as redações dos artigos 165, 276 e 306 do CTB, foi praticamente abolida a faixa de tolerância na esfera administrativa( ${ }^{(7)}$ e fixada uma dupla proteção criminal, definindo-se dois Crimes de Embriaguez ao Volante: o primeiro, por dirigir com excesso de alcoolemia (em que a faixa de tolerância é de $6 \mathrm{dg} / \mathrm{L}$ ); e o segundo, por conduzir veículo sob influência de qualquer substância psicoativa (inclusive o álcool) ${ }^{(8)}$.

Sendo atualizada a Lei Seca (por meio da Lei n. 12.760, de 20.12.2012), foi publicada a Resolução n. 432/13, do CONTRAN, que buscou reduzir ainda mais a faixa de tolerância, fixando-a em zero (na hipótese de exame de sangue) e em $0,05 \mathrm{mg}$ de álcool por litro de ar expirado dos pulmões (na hipótese de exame do etilômetro).

Percebe-se que o legislador pátrio vem reduzindo a faixa tolerância em relação à Embriaguez ao Volante, com a esperança de conscientizar o povo brasileiro sobre os riscos relacionados ao fato de dirigir sob influência de álcool.

\section{OMS RECOMENDA: TOLERÂNCIA ZERO PARA JOVENS CONDUTORES}

Merece destaque a recomendação oferecida pela $\mathrm{OMS}^{15}$ para a fixação de tolerância zero ou faixas de tolerância com índices ainda mais reduzidos aos jovens condutores (com menos de 25 anos de idade) ${ }^{(9)}$ ou principiantes. Essa medida pode proporcionar redução de 4 a $24 \%$ no volume de colisões envolvendo pessoas dessa faixa etária ${ }^{15}$. No ano de 2009, dezenove Estados (membros das Nações Unidas) já haviam incorporado essa orientação a suas legislações.

Realizando um brevíssimo retrospecto histórico das normas relacionadas à embriaguez ao volante, no Brasil, tem-se uma evolução muito significativa, tanto na esfera administrativa quanto na criminal.

No âmbito administrativo (como acima destacado), houve redução da faixa de tolerância inicialmente fixada em $8 \mathrm{dg} / \mathrm{L}$ para $6 \mathrm{dg} / \mathrm{L}$ (seis decigramas de álcool por litro de sangue) e, em 2013, a tolerância do legislador aproximou-se do ideal zero. Essa política de Segurança Viária, em que se observa a criação de normas mais rígidas, constitui ação concreta do Estado brasileiro em direção à realização dos objetivos propostos para a Década Mundial de Ações para Segurança Viária: “estabilizar e, posteriormente, reduzir os índices de vítimas fatais no trânsito em todo o mundo"22 (parágrafo $2^{\circ}$ ).

A via de acesso ao Trânsito Seguro encontrase sinalizada pelas Nações Unidas, que reconheceu a Embriaguez ao Volante como um dos mais graves fatores de risco à segurança viária ${ }^{(10)}$. Espera-se que o gigante denominado Brasil adote as orientações da OMS e assuma seu papel durante a Década de Ações para Segurança Viária:

"reconhecer (internalizando no fundo da alma e do coração do povo brasileiro) a seriedade e a natureza (social e coletiva) da utilização das vias terrestres; revelar ao Estado sua função de Enforcement e, como tal, seu dever de promover ações visando assegurar todos os direitos inerentes aos seres humanos e garantir a realização do trânsito em condições seguras"24 (p.111).

\section{COMO DETERMINAR A QUANTIDADE DE ÁLCOOL INGERIDA?}

O questionamento realizado na Introdução contempla algumas informações de natureza objetiva, que permitem determinar a quantidade de álcool introduzida no organismo com a ingestão de dois cálices de vinho tinto.

As bebidas alcoólicas apresentam distintas quantidades de álcool em suas composições, denominada teor alcoólico (ou graduação alcoólica). Apenas a título de exemplo, destaca-se o teor alcoólico de algumas bebidas comumente ingeridas no Brasil: (i) cerveja, de 3 a 6\%; (ii) vinho branco, 10\%, (iii) vinho tinto, $12 \%$; (iv) aguardente, whisky, e outras bebidas destiladas, de 35 a $50 \%$. O teor alcoólico deve, necessariamente, constar do rótulo da bebida ${ }^{(11)}$ (expresso em \% ABV, ou seja, alcohol by volume).

\footnotetext{
${ }^{(7)}$ A faixa de tolerância foi eliminada da redação do art. 165 do CTB; porém, o Decreto n. 6.488, de 19.06.2008, fixou a margem de tolerância em $02 \mathrm{dg} / \mathrm{L}$, até a publicação da Res. 432/2013 do CONTRAN.

${ }^{\left({ }^{8}\right)}$ Em relação aos dois Crimes de Embriaguez ao Volante, consultar Honorato ${ }^{21}$.

(9) A referência aos 25 anos de idade tem por fundamento a exposição de Castillo, Dominguéz e Uclés, por demonstrar que "Los menores de 25 años y los mayores de 60 son más vulnerable al alcohol"s.

${ }^{(10)} \mathrm{O}$ Informe Mundial sobre Prevenção de Traumatismos Causados pelo Trânsito ${ }^{23}$ identificou os seguintes fatores de risco: velocidade inadequada e excessiva, embriaguez ao volante, não uso do cinto de segurança e de sistema de retenção para crianças, falta do capacete de segurança.

(11) Por determinação do art. 19, inc. IX, do Regulamento da Lei n. 8.918 (aprovado pelo Dec. 2.314/97).
} 
Um cálice (ou taça) para vinho possui capacidade para armazenar em torno de $90 \mathrm{~mL}^{25}$. Considerando que foi ingerido o conteúdo de dois cálices, tem-se a ingestão de $180 \mathrm{~mL}$ (ou $180 \mathrm{~cm}^{3}$ ) de vinho. Para determinar a quantidade de álcool ingerida em cada dose de bebida alcoólica, realizam-se duas operações aritméticas: na primeira, para determinar o volume de álcool consumido, deve-se multiplicar o volume ingerido (em $\mathrm{mL}$ ) pelo teor alcoólico da bebida (\%ABV). Assim: (teor alcoólico\% $\mathrm{x}$ volume $)=$ mililitros de álcool. No caso específico: $(12 \% \times 180)=(12 \times 180) \div 100=21,6 \mathrm{~mL}$.

A segunda decorre do peso específico (ou densidade) do álcool, em que o volume de 1 mililitro pesa o equivalente a 0,79 gramas $^{6}$. Então, o volume de álcool (em mililitros) obtido na primeira operação deve ser multiplicado por sua densidade $(\mathrm{d}=\mathrm{m} \div \mathrm{v})^{(12)}$, chegandose à massa (ou quantidade em gramas) de álcool ingerido.

Os dois cálculos (acima mencionados) podem ser realizados por meio da seguinte fórmula: (teor alcoólico $\%$ $\mathrm{x}$ volume $\mathrm{x} 0,79)=$ gramas de álcool .

Aplicando-se a fórmula ao caso concreto, e tendo em consideração que foram ingeridos dois cálices com cerca de $90 \mathrm{~mL}$ de vinho (em cada um deles, totalizando $180 \mathrm{~mL}$ ou $180 \mathrm{~cm}^{3}$ ), e que o vinho tinto apresenta $12 \%$ de teor alcoólico, tem-se que a quantidade total de álcool ingerido (A) foi de aproximadamente $[(12 \% \times 180 \times 0,79)$ ou $(12 \times 180 \times 0,79) \div 100=] 17,064 \mathrm{~g}$.

Aplicando-se essa informação à Fórmula de Widmark (em que $A=$ p.r.c) tem-se identificado o primeiro elemento da equação, relacionado ao problema exposto na Introdução: $17,064=$ p.r.c. Os demais elementos serão identificados nos itens seguintes.

Assim, pode-se afirmar que, ao ingerir o conteúdo de dois cálices de vinho tinto (a 12\% de teor alcoólico), têm-se no organismo 17,064 gramas de álcool, que serão distribuídos em todos os órgãos e tecidos por meio de difusão.

\section{DIFUSÃO EM BUSCADO PONTO DE EQUILÍBRIO}

$\mathrm{Na}$ terceira fase da intoxicação alcoólica (após a ingestão e a absorção), tem início a difusão; ou seja, processo biológico pelo qual "o álcool vai ser distribuído por todo o organismo pela corrente sanguínea"4 (p.299).

A distribuição do álcool, como acima mencionado, normalmente completa-se em até uma hora após a ingestão da substância. Por cautela, Widmark ${ }^{2}$ recomenda que seja observado um intervalo de $1 \mathrm{~h} 30 \mathrm{~min}$ (entre a ingestão do álcool e a coleta da amostra) para a completa distribuição do álcool pelas células, atingindo-se o equilíbrio de difusão, ou seja, "instante em que a absorção se equilibra com a difusão" (p.318), assegurando a efetiva distribuição do álcool por todo o organismo.

Atingido o ponto de equilíbrio, pode-se promover a coleta da amostra (por meio de sangue ou ar alveolar) para a realização do exame de alcoolemia e a determinação da Taxa de Álcool no Sangue (TAS).

\section{DIFUSÃO, SIM; PORÉM, COM DISTRIBUIÇÃO HETEROGÊNEA: FUNDAMENTO DO QUOCIENTE $R$}

Importante destacar, desde logo, que a difusão ocorre por todo o organismo; porém, a distribuição do álcool não se realiza de forma homogênea (ou idêntica) em todas as células e órgãos, variando de acordo com a quantidade de água e de gordura no tecido ${ }^{2}$. Segundo Simonin", "El reparto del etanol es sensiblemente proporcional al contenido en agua de los tejidos (Nicloux), y a su vascularización; es inversamente proporcional a su riqueza en grasa. [...]" (p.568).

Essa constatação é particularmente relevante, por constituir o fundamento científico do quociente de redução (r), a ser empregado na Fórmula de Widmark, para determinar a quantidade de álcool no organismo: $A=$ c.p.r. Segundo o Widmark ${ }^{2}$.

"It is most important to know the quotient between the mean alcohol concentration of the whole body and that of the blood. With knowledge of this and the body weight, then from the value of the alcohol concentration in the blood one can calculate the total amount of alcohol in the organism. That is, if: [organism] / [blood] $=r$, then the total amount of alcohol in the organism, $a$, is equal to the product of the alcohol concentration of the blood, $c$, the body weight, $p$, and the quotient $r$ : $\mathrm{A}=$ c.p.r." (p.18).

$\mathrm{O}$ quociente de redução, portanto, "representa la relación de la distribución del alcohol entre la sangre y el cuerpo, menos rico en agua, por consiguiente en alcohol"3 (p.589).

Pesquisas sobre a heterogênea distribuição do álcool pelo organismo permitiram a Widmark ${ }^{2}$ determinar a razão existente entre a quantidade de álcool no sangue e o volume total de álcool no organismo. Essa constante relação (ou razão) foi denominada quociente $r^{(13)}$. Segundo Widmark ${ }^{2}$, o valor médio do quociente de redução é de 0,68 para pessoas do sexo masculino (com um desvio de $\pm 0,085)$ e de 0,55 para o sexo feminino (com possível variação $\pm 0,055$ ).

$\mathrm{O}$ fato de o quociente de redução ser menor

\footnotetext{
(12) "Chama-se densidade absoluta (d) ou massa específica de um elemento ao quociente entre sua massa (m) e seu volume (v). Portanto: $\mathrm{d}=\mathrm{m} / \mathrm{v}$ "26. ${ }^{(13)}$ Sadler , por sua vez, prefere identificar o quociente de redução como "Fator Widmark (WF)": "The Widmark Factor (WF) is an estimate of body water content. The mean experimental values are 0.68 for men and 0.55 for women" (p.4).
} 
para as mulheres encontra-se diretamente relacionado a três circunstâncias essenciais²: (i) maior quantidade de gordura corporal e baixa solubilidade do álcool nesse tipo de tecido; (ii) menor quantidade de água por quilo de peso no organismo feminino, e (iii) menor atividade de enzimas na mucosa gástrica ${ }^{(14)}$.

Como se percebe, a distribuição do álcool no organismo masculino $(0,68 \pm 0,085)$ é distinta do feminino $(0,55 \pm 0,055)$. Tal fato produzirá reflexos sobre a resposta aos questionamentos realizados na Introdução dessa exposição, pois dever-se-á levar em consideração o fato de a bebida alcoólica ter sido ingerida por pessoa do sexo feminino (em que o quociente de redução $(r)=0,55$ $\pm 0,055$ deve ser aplicado à fórmula: $\mathrm{A}=$ c.p.r), com peso aproximado de 60 quilogramas, de modo que $A=c .60 \mathrm{~kg}$. $(0,55 \pm 0,055)$.

\section{DETERMINANDO A TAXA DE ÁLCOOL NO SANGUE (TAS em dg/L)}

Considerando que foram ingeridos $180 \mathrm{~mL}$ de vinho tinto, com teor alcoólico de $12 \%$, tem-se que a quantidade total de álcool no organismo (A) foi de aproximadamente 17,064g (como acima demonstrado, por meio do cálculo: $(12 \%$ x $180 \times 0,79)=\mathrm{A})$.

Transportando essas informações para a Fórmula de Widmark, tem-se que $A=c . p . r$, ou seja, $17,064 \mathrm{~g}=$ c.60kg. $(0,55 \pm 0,055)$. Logo, a quantidade de álcool ( $c$, em gramas) por quilograma de sangue de minha mãe, na noite em que ingeriu os dois cálices de vinho, era de 0,47 a $0,57 \mathrm{~g} / \mathrm{kg}$ (gramas de álcool por quilo de sangue $)^{(15)}$.

A Fórmula de Widmark permite determinar a quantidade de álcool no sangue $(c)$, expressa em g/ $\mathrm{kg}$ (gramas de álcool por quilo de sangue). O sistema atualmente utilizado no Brasil, no entanto, prevê a Taxa de Álcool no Sangue (TAS) aferida em gramas por litro de sangue ( $\mathrm{g} / \mathrm{L}$ ou dg/L).

Para tanto, Simonin ${ }^{3}$ adverte para a necessidade de converter o resultado com base na densidade do sangue, em que 1 litro de sangue corresponde a 1,056kg. Dividindose a massa (ou quantidade em gramas) de álcool aferida (no item anterior) pela densidade do sangue ${ }^{(16)}$, tem-se uma TAS entre $[0,47 \div 1,056=] 0,445 \mathrm{~g} / \mathrm{L}$ e $[0,57 \div 1,056=]$ $0,539 \mathrm{~g} / \mathrm{L}$. Assim, a TAS de minha mãe decorrente da ingestão da bebida descrita na Introdução encontrava-se entre 4,45 e 5,39 dg/L (decigramas de álcool por litro de sangue). Caso ela conduzisse veículo automotor em via pública, com esse nível de alcoolemia, estaria cometendo infração gravíssima de trânsito (descrita no art. 165 do CTB) e sob suspeita de dirigir sob a influência de álcool (na esfera do Direito Criminal).

Para aqueles que evitam enfrentar cálculos matemáticos, Sadler $^{6(17)}$ oferece uma orientação simplificada (e interessante): considerando que cada dose standard de bebida contem aproximadamente 8 gramas de álcool puro, uma unidade de álcool poderá elevar a Taxa de Álcool no Sangue de uma pessoa do sexo masculino em $1,5 \mathrm{dg} / \mathrm{L}$ e a TAS de uma mulher em $2 \mathrm{dg} / \mathrm{L}$.

A sugestão do autor é interessante e leva em consideração homens com 75 quilos $(8 \mathrm{~g}=75 \mathrm{kgx} 0,68 \mathrm{x} c$, em que $c=1,56 \mathrm{dg} / \mathrm{kg}$ e TAS $=1,56 \div 1,056=1,48 \mathrm{dg} / \mathrm{L})$ e mulheres com 70 quilos de peso $(8 \mathrm{~g}=70 \mathrm{Kgx} 0,55 \mathrm{x} c$, em que $c=2,07 \mathrm{dg} / \mathrm{kg}$ e TAS $=1,96 \mathrm{dg} / \mathrm{L})$. Na hipótese de uma pessoa do sexo feminino, e com 60 quilos de peso (como descrito na Introdução), a TAS seria elevada em $(8 \mathrm{~g}=[60 \times 0,55 \times c] \div 1,056) 2,3 \mathrm{dg} / \mathrm{L}$ para cada taça ingerida, totalizando 4,6dg/L (decigramas de álcool por litro de sangue). Esse índice de alcoolemia encontra-se abrangido pela faixa de 4,45 e 5,39 dg/L, acima determinada a partir da Fórmula de Widmark.

Resta determinar o período de vedação, ou seja, quanto tempo o organismo necessita para promover a desintoxicação dessa quantidade de álcool, reduzindo a TAS a zero, e permitindo a condução de veículo automotor com segurança.

\section{A CONFIRMAÇÃO DA LEI DE HENRY E SUA APLICAÇÃO NA FISCALIZAÇÃO DE ALCOOLEMIA}

Outro ponto que merece destaque nas pesquisas de Widmark ${ }^{2}$ volta-se à afirmação de uma constante relação (ou razão) entre a Taxa de Álcool no Sangue (TAS) e a concentração de álcool no ar alveolar (ou seja, ar pulmonar/TAS); chegando a afirmar que "pode-se determinar a quantidade de álcool no sangue determinando-se a quantidade de álcool constante no ar exalado dos pulmões" (p.37).

Essa constante já havia sido reconhecida pelo químico britânico William Henry (1775-1836), no ano de 1801, e passou a ser denominada Lei de Henry, com

\footnotetext{
(14) Sobre essas três circunstâncias vale destacar a exposição de Castillo, Domínguez e Uclés ${ }^{8}$. (p.49-50).

${ }^{(15)}$ Considerando o desvio ou variação da Fórmula $( \pm 0,055)$, dois cálculos são necessários. Primeiro acrescentando-se 0,055 , tem-se: $17,064=\mathrm{c}$. 60. $(0,55+0,055)$, ou seja, c=0,470g. Depois, subtraindo-se 0,055 obtém-se: $17,064=\mathrm{c} .60 .(0,55-0,055)$, em que c=0,574g. Daí, $c$ variar entre 0,47 a $0,57 \mathrm{~g} / \mathrm{kg}$.)

(16) Como destacado anteriormente (12, p. 117): densidade = massa $\div$ volume $(\mathrm{d}=\mathrm{m} \div \mathrm{v})$. Assim, $\mathrm{d}=\mathrm{m} \div \mathrm{v}$, ou $\mathrm{d} . \mathrm{v}=\mathrm{m}$, ou $\mathrm{v}=\mathrm{m} \div \mathrm{d}$. Por isso divide-se a massa (ou quantidade) de álcool pela densidade do sangue $(=1,056)$ para determinar-se a TAS em volume $($ ou seja, $\mathrm{g} / \mathrm{L})$ : TAS $=c \div 1,056$.).

(17) " 1 unit = a standard drink = approx $8 \mathrm{~g}$ of pure alcohol. [...]. Rule of thumb: One unit of alcohol will elevate alcohol concentration the blood concentration within the first hour by $15 \mathrm{mg}$ per $100 \mathrm{~mL}$ in a man and by $20 \mathrm{mg}$ per $100 \mathrm{~mL}$ in a woman" (p.02-04).
} 
o seguinte enunciado ${ }^{27}$ : "Em temperatura constante, a solubilidade de um gás num líquido é diretamente proporcional à pressão do gás. Ou, matematicamente: $S=k P$, onde $k$ é uma constante de proporcionalidade que depende da natureza do gás e do líquido e, também, da temperatura" (p.14).

A partir da Lei de Henry, pesquisas revelaram a existência de uma constante proporcionalidade entre a Taxa de Álcool no Sangue (TAS) e a concentração de álcool no ar alveolar, à razão de 1 para 2000 (ou seja: $1 / 2000$ ), e este índice tem sido utilizado na calibragem (e aferição) dos aparelhos de medição, denominados etilômetros. Segundo Simonin ${ }^{3}$ :

"Los métodos respiratorios de evaluación del estado de impregnación derivan de la ley de Henry sobre los intercambios entre un gas, un vapor (alcohol) y un líquido (sangre). Hay, pues, una relación constante entre la cantidad de alcohol que se encuentra en el mismo volumen de aire alveolar y de la sangre; esta relación es de 1/2000; asimismo 1 c. c. de sangre contiene tanto alcohol como 2.000 c. c. de aire alveolar" (p.581-2).

A legislação brasileira (por meio do Decreto $n$. 6.488, de 19.06.2008) valeu-se desse conhecimento científico para estabelecer a equivalência entre os resultados dos exames laboratoriais e os laudos emitidos pelos etilômetros: "Art. 20. Para os fins criminais de que trata o art. 306 da Lei n. 9.503, de 1997 - Código de Trânsito Brasileiro, a equivalência entre os distintos testes de alcoolemia é a seguinte: I - exame de sangue: concentração igual ou superior a seis decigramas de álcool por litro de sangue; ou II - teste em aparelho de ar alveolar pulmonar (etilômetro): concentração de álcool igual ou superior a três décimos de miligrama por litro de ar expelido dos pulmões"(18).

Como se percebe nos incisos I e II, da norma acima transcrita, a relação entre o resultado do etilômetro $(0,3$ $\mathrm{mg} / \mathrm{L}$ ) e os exames laboratoriais (sangue e urina $-6 \mathrm{dg} / \mathrm{L}$ ) encontra-se à razão de 1/2000. A Lei de Henry, portanto, encontra-se presente na fiscalização de trânsito em dois momentos distintos: tanto na aferição e calibragem dos equipamentos de medição, quanto no momento da elaboração da norma jurídica.

A validade dos testes de alcoolemia, em especial dos exames realizados por meio de aparelhos de ar alveolar (i.e., etilômetros), já se encontra consagrada pela doutrina ${ }^{7,21}$ e pela orientação do Superior Tribunal de Justiça ${ }^{(19)}$.

\section{METABOLISMO: A BATALHA DO ORGANISMO CONTRA O ÁLCOOL}

Após as fases de ingestão, absorção e difusão (ou distribuição) do álcool, o organismo inicia um longo período de desintoxicação, que pode durar de 15 a 20 horas $^{3}$, promovido por dois mecanismos de defesa: eliminação e etiloxidação.

O processo de eliminação é realizado pelos pulmões e pelos rins (que eliminam parte do álcool por meio da urina). Segundo $\operatorname{Simonin}^{3}$, a eliminação não representa mais que 1 a $5 \%$ da desintoxicação (podendo alcançar $10 \%$ por hiperventilação pulmonar). Para Arbenz ${ }^{4}$, "o total da eliminação não vai além de $15 \%$ " (p.299). O pequeno alcance do processo de eliminação revela a importância da etiloxidação, como instrumento de defesa do organismo contra o álcool ingerido e distribuído por todo o corpo.

Percebe-se uma grande mudança na quarta fase da intoxicação alcoólica: nas três primeiras fases (i.e., ingestão, absorção e difusão) ocorre um grande (e rápido) aumento da quantidade de álcool no organismo. Acionados os mecanismos de defesa, esse fenômeno inverte e, sendo interrompida a ingestão de bebida alcoólica, a concentração alcoólica será lenta e linearmente reduzida. Esses dois distintos momentos (denominados absortive period e post-absortive period), então, podem ser representados graficamente por meio da Curva Alcoolêmica, como consta da figura abaixo, elaborada por Widmark ${ }^{2}$ :

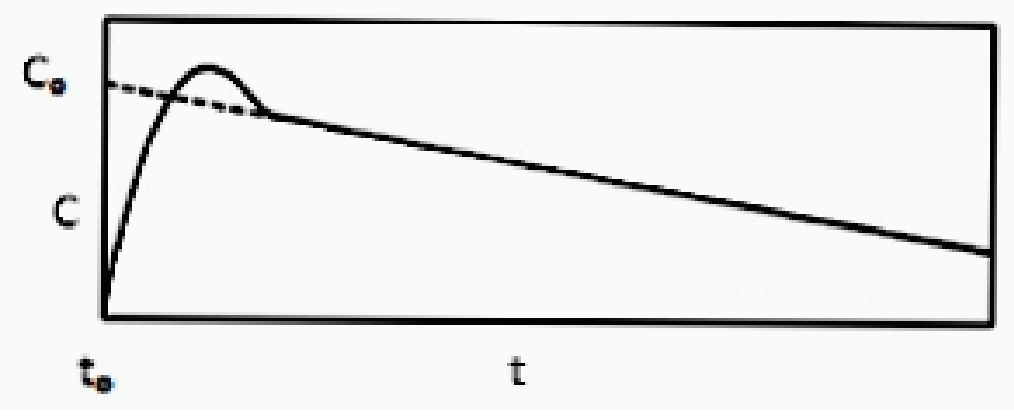

\footnotetext{
${ }^{(18)}$ A equivalência descrita no Decreto n. 6.488/2008 passou a ser expressamente prevista no art. 306, § $1^{\circ}$, do CTB, após a publicação da Lei n. 12.760, de 20.12.2012.

(19) STJ. HC 202653/RJ. Julg. 23.08.2011; STJ. RHC n. 26.432/MT. Julg.19.11.2009; STJ. RHC n. 117.230/RS. Julg.23.11.2010; e STJ. REsp. 1208112/MG. Julg. 24.06.2011.
} 


\begin{abstract}
Afirma França ${ }^{5}$ que:
"é muito importante também conhecer a chamada curva alcoolêmica, pois a partir dela pode-se fundamentar melhor o diagnóstico médico-legal da embriaguez. A primeira linha (curva de difusão ou absorção) é ascendente e corresponde ao período de absorção, durante cerca de 30 a 60 minutos, isso quando se trata de absorção única. Em caso de absorções sucessivas, teremos uma linha quebrada e escalonada, em face das continuadas ingestões. [...]. E uma linha descendente (curva de eliminação), de forma regular e gradativa, que corresponde ao período de desintoxicação e em que predomina o processo de oxidação, tendo início a partir de 1 hora e 30 minutos da ingestão" (p.318).
\end{abstract}

A primeira parte da figura (acima destacada) revela um rápido aumento da quantidade de álcool, em razão da ingestão da bebida alcoólica e dos processos de absorção e difusão. Daí o gráfico ser representado por uma linha ascendente, com forte tendência à verticalização, até que seja atingido o equilíbrio de difusão. A segunda parte da figura inicia no ponto $(C o)$ em que a concentração de álcool encontra o equilíbrio de difusão; descrevendo, a partir desse momento, uma suave reta descendente (linear e gradativa), representando o constante e linear processo de desintoxicação.

O ponto Co constitui o marco divisório entre as fases iniciais da intoxicação alcoólica e a fase descendente do gráfico (i.e., fase de desintoxicação), e sua projeção sobre a coordenada do tempo representa o termo inicial (Ti) do período de vedação.

\section{A LENTA CONVERSÃO DO ÁLCOOL: LINEAR E INDEPENDENTE DE FATORES EXTERNOS}

Discorrendo sobre a "velocidade das reações químicas e os fatores que a influenciam", Widmark ${ }^{2}$ baseia seus estudos em leis da cinética ${ }^{(20)}$, em especial a denominada zero-order reaction (em que se afirma que a taxa de conversão do álcool no organismo independe de sua concentração $)^{(21)}$, para demonstrar que a concentração de álcool no organismo, após os períodos de absorção e de difusão, busca um ponto de equilíbrio e, a partir daí, reduz de forma linear (alguns autores chegam a afirmar que a redução faz-se "de forma regular e gradativa" (p.318) e "independente da quantidade de álcool consumida"'2 (p.67-68).

Simonin $^{3}$ afirma que a conversão (ou metabolismo) independe de fatores externos relacionados à temperatura ambiente ou à realização de atividades físicas. Diversamente, Castillo et al. ${ }^{8}$ consideram as horas noturnas como fator potencializador dos efeitos do álcool, decorrente da redução do metabolismo durante o sono. Segundo os autores ${ }^{8}$ :

"El sujeto tiene unos ciclos de su actividad biológica, que varían sensiblemente de la noche al día o de la mañana a la tarde. Por el día - en general -, todos los mecanismos biológicos están más activos que por la noche. Por ejemplo, una persona que haya bebido seis combinados y se acuesta a dormir ocho horas se levantará con un índice de alcoholemia muy superior al que tendría durante cualquier otro día, estando activa también ocho horas, lo que supone un grave riesgo para la seguridad vial, [...]. Ello es debido a la ralentización que se produce en la metabolización durante el sueño" (p.54-5).

Em relação ao gênero, Widmark ${ }^{2}$ afirma que o processo de oxidação atua de forma semelhante nos organismos masculino e feminino, apresentando uma variação inexpressiva.

Um dos fatores pessoais (ou interno) que pode influir no ritmo da desintoxicação etílica é a idade. Castillo, Domínguez e Uclés ${ }^{8}$ revelam que:

"Los menores de 25 años e los mayores de 60 son más vulnerables al alcohol. [...]. No solo el peso de la persona influye en la distribución del alcohol, sino también la configuración muscular que tenga. Así, la diferente proporción de musculatura y grasas con el mismo peso influye en el proceso de distribución del alcohol en el cuerpo. [...]. Las investigaciones demuestran que las personas menores de 16 o 18 años y los mayores de 65 años tienen peor defensa orgánica frente al alcohol y son, en general, más sensibles a sus efectos, de manera que controlan peor los deterioros que este tóxico produce en las capacidades psicofísicas necesarias para conducir" (p.55-6).

Retornando aos questionamentos realizados na Introdução, cumpre observar que o fato de os cálices de vinho terem sido ingeridos por uma pessoa com mais de 60 anos de idade e a circunstância de ela haver, em seguida, realizado repouso (dormindo durante o período noturno) podem alterar a velocidade de conversão (metabolismo), reduzindo ainda mais a taxa de etiloxidação e aumentando o período de vedação.

\section{O FATOR B DE CONVERSÃO E A TAXA DE ETILOXIDAÇÃO}

A habilidade que o organismo humano possui de converter o álcool ingerido (e difundido pelas células) recebe a denominação de metabolismo e o ritmo (ou

\footnotetext{
${ }^{(20)}$ Por cinética entende-se 28 "parte da físico-química que estuda a velocidade das reações químicas e os fatores que a influenciam".

(21) "[...]. The dual experiments described below show that the concentration of the alcohol consumed has no effect in the determination of $\beta$ [the drop in blood concentration per minute]"2 (p.66).
} 
velocidade) em que esse processo de transformação ocorre constitui a taxa de oxidação, identificado por Widmark $^{2}$ como fator $\beta$ de conversão. Diante da Curva Alcoolêmica, o fator $\beta$ pode ser assim representado na Figura 1.

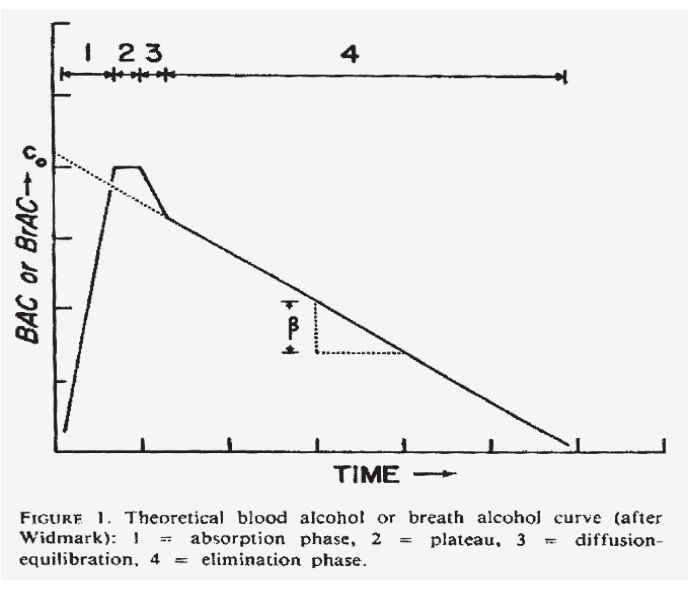

Figura 1. Figura denominada "The Widmark Curve" por Dubowski $^{29}$

Não há que se confundir o fator $\beta$ com o quociente de redução $(r)$, inserto na fórmula de Widmark. O primeiro caracteriza a habilidade de o indivíduo converter o álcool ingerido e promover a desintoxicação (i.e., taxa de etiloxidação), enquanto o quociente $r$ refere-se à fase de difusão e à diferente distribuição do álcool nos organismos masculino e feminino ${ }^{2}$.

O sistema de defesa do organismo, portanto, realiza a conversão do álcool de forma linear, independente do gênero, da concentração de álcool ingerido ou de outros fatores externos (como temperatura ambiente ou realização de atividades físicas).

Embora não esteja sujeito a fatores externos, o ritmo do metabolismo apresenta variações pessoais (internas ou orgânicas). Desse modo, deve-se ter em consideração fatores inter-individuais ${ }^{30}$ potencializadores dos efeitos do álcool relacionados à idade (v.g., jovens menores de 25 anos e pessoas maiores de 60 anos), as condições de saúde do indivíduo (em especial em relação à saúde do fígado, responsável pela produção das enzimas que oxidam o álcool ingerido, transformando-o em outras substâncias)(22), bem como a redução do metabolismo durante o sono. Estudos realizados por Sadler ${ }^{6}$ demonstram que a taxa de etiloxidação pode variar de 0,1 a $0,4 \mathrm{~g} / \mathrm{L}$ por hora.

Em relação ao fator $\beta$, Widmark ${ }^{2}$ sustenta que a taxa de oxidação é de 0,15 por hora. Por sua vez,
Arbenz $^{4}$ afirma "que a etil-oxidação é mais ou menos constante $(0,22 \mathrm{~g} / \mathrm{lt} /$ hora no sexo masculino e 0,20 no sexo feminino)" (p.301).

Adotando-se a orientação mais conservadora de Widmark ${ }^{2}$, em que o fator $\beta$ de conversão é de $1,5 \mathrm{dg} / \mathrm{L}$ por hora, é possível determinar (com boa margem de segurança) a duração da fase de desintoxicação e, desse modo, o tempo (em horas) em que a pessoa que ingeriu bebida alcoólica encontrar-se-á sob efeito do álcool e não poderá dirigir veículo, de forma segura e sem violar a legislação de trânsito.

A fase de desintoxicação (medida em horas) corresponde à Taxa de Álcool no Sangue (TAS) dividida pelo fator $\beta$ de conversão, ou seja: TAS $\div$ fator $\beta$, ou TAS $\div 1,5 \mathrm{dg} / \mathrm{L}$.

\section{IDENTIFICANDO O PERÍODO DE VEDAÇÃO POR MEIO DO COEFICIENTE DE ETILOXIDAÇÃO}

No presente estudo, considera-se período de vedação o tempo (em horas) que o organismo necessita para promover a desintoxicação do álcool ingerido (juntamente com a bebida), de modo a reduzir a TAS a zero e permitir a condução de veículo automotor com segurança. O período de vedação tem início com a ingestão da primeira dose da bebida e somente encerra com a conclusão do processo de desintoxicação.

Para determinar a extensão desse período, três cálculos precisam ser realizados: primeiro, na fase de ingestão, para determinar a quantidade de álcool (em gramas) trazida ao organismo com a bebida alcoólica.

No presente estudo, tendo em consideração o teor alcoólico do vinho tinto (12\%), o volume contido em duas taças (com aproximadamente $90 \mathrm{~mL}$ cada uma delas) e a densidade do álcool (peso específico $=0,79$ ), concluiu-se que a quantidade de álcool ingerida foi 17,064 gramas $[=(12 \% \times 180 \times 0,79)]$.

O segundo cálculo, decorrente das fases de absorção e de difusão do álcool no organismo, tem em consideração o quociente de redução $(r)$ da Fórmula de Widmark $(A=p . r . c)$ e a densidade do sangue $(1,056=\mathrm{m} \div \mathrm{v})$, permitindo determinar a quantidade de álcool por litro de sangue, conhecida como TAS (em dg/L). A distribuição de 17,064 gramas de álcool, pelo corpo de uma pessoa do sexo feminino (em que o quociente $r=0,55 \pm 0,055$ ), com 60 quilos de peso, resultou (nos dois cálculos acima realizados) uma TAS entre 4,45 a 5,39 dg/L.

Por fim, considerando o fator idade e o período de repouso noturno (que podem atuar como circunstâncias ou fatores redutores do metabolismo e potencializadores dos efeitos do álcool), deve-se adotar o fator $\beta$ de $1,5 \mathrm{dg} / \mathrm{L}$

\footnotetext{
${ }^{(22)}$ Durante o processo de desintoxicação, são executadas "fases continuadas de oxidações, transformando-se [o álcool] em aldeído, ácido acético, gás carbônico e água. Nesse processamento são desprendidas 7,2 calorias por grama de álcool”5 (p.318).
} 
(por hora), como coeficiente de etiloxidação. Nesse caso, a fase de desintoxicação (em relação ao fato descrito na Introdução) será realizada [TAS $\div 1,5]$ durante 3 horas a $3 \mathrm{~h} 36 \mathrm{~min}^{(23)}$.

Identificado o tempo necessário para que o organismo possa eliminar e oxidar o álcool ingerido (a partir das informações objetivas e pessoais constantes da Introdução), resta estabelecer o momento do início da contagem desse prazo para conhecer o período de vedação.

\section{O TERMO INICIAL (Ti) DA FASE DE DESINTOXICAÇÃO E A RESPOSTA AOS QUESTIONAMENTOS}

Retornando à representação gráfica das fases da intoxicação alcoólica, França ${ }^{5}$ esclarece que, "no instante em que a absorção se equilibra com a difusão, a concentração de álcool no sangue mantém-se uniforme. A isto chama-se equilíbrio de difusão. A partir daí, o organismo humano começa o processo de desintoxicação" (p.318). O termo inicial da fase de desintoxicação encontra-se no ponto $C o$ da Curva Alcoolêmica de Widmark $^{2(24)}$ que corresponde à concentração (de álcool) no momento em que o organismo atinge o equilíbrio de difusão e inicia a fase descendente do gráfico. Projetandose essa concentração $C o$ sobre a coordenada do tempo, tem-se o termo inicial (Ti), ou seja, momento em que o organismo atinge o ponto de equilíbrio $(\mathrm{Co})$ e inicia a fase de desintoxicação alcoólica.

Diante da impossibilidade fática de determinar, em cada caso concreto, o exato momento em que o organismo alcança o ponto de equilíbrio Ti (e inicia o post-absortive period), buscou-se um parâmetro nas pesquisas realizadas por consagrados autores para estimar esse prazo.

Os estudos de Widmark ${ }^{2}$ revelaram que, na maioria dos casos pesquisados, o equilíbrio de difusão foi alcançado em até 30 minutos após a ingestão da bebida. Versando sobre a Curva de Alcoolemia, Sadler ${ }^{6}$ indica o equilíbrio de difusão entre 15 e 30 minutos após o início da absorção.

Esse período, no entanto, é contestado por diversos autores. Segundo França ${ }^{5}$, o período de desintoxicação somente tem início a partir de 1 hora e trinta minutos da ingestão; enquanto Dubowski ${ }^{29}$ promove severas críticas ao "padrão Widmark", afirmando que não é possível estabelecer quando um indivíduo encontra-se na fase de absorção ou de eliminação. Observa-se, ainda, que o próprio Widmark ${ }^{2}$ menciona que o equilíbrio de difusão ocorre entre 1 hora e $01 \mathrm{~h} 30 \mathrm{~min}$, fazendo-se necessário aguardar esse período para a coleta das amostras.

Diante dessa divergência, e sob a orientação ${ }^{(25)} \mathrm{do}$ princípio do Trânsito em Condições Seguras ${ }^{(26)}$, adota-se no presente estudo a orientação mais segura e presumese, então, o termo inicial da fase de desintoxicação (Ti) em 1h30min após a interrupção da ingestão da bebida.

Fixado o termo a quo do post-absortive period, faz-se mister adicionar esse prazo (indispensável para alcançar o equilíbrio de difusão) ao tempo necessário para que o organismo possa acionar o sistema de defesa, eliminando e oxidando o álcool ingerido (fase de desintoxicação etílica) para, então, conhecer o período de vedação $(\mathrm{PV})$. Pode-se dizer que $\mathrm{PV}=T i+(\mathrm{TAS} \div$ fator $\beta)$, ou seja, que o período de vedação $(\mathrm{PV})=1 \mathrm{~h} 30 \mathrm{~min}+$ (TAS $\div 1,5)$

Reunindo as informações constantes na Introdução e os cálculos realizados nos itens seguintes, pode-se determinar o tempo necessário para que o organismo de uma pessoa do sexo feminino, com aproximadamente 60 quilos de peso, possa oxidar e eliminar o álcool ingerido em duas taças de vinho tinto, até atingir TAS zero:

$\mathrm{A}=($ teor alcoólico $\% \mathrm{x}$ volume $\mathrm{x}$ densidade álcool $)$

$A=(12 \% \times 180 \times 0,79)=(12 \times 180 \times 0,79) \div 100$

$\mathrm{A}=17,064 \mathrm{~g}$

$\mathrm{A}=c . p . r$ (Fórmula de WIDMARK)

$17,064 \mathrm{~g}=c .60 \mathrm{~kg} .(0,55 \pm 0,055)$

$c=0,47$ a $0,57 \mathrm{~g} / \mathrm{kg}$ (gramas de álcool por quilo de sangue)

$c \div 1,056=\mathrm{TAS}$

$\mathrm{TAS}=4,45$ a 5,39 dg/L (decigramas de álcool por litro de sangue)

$\mathrm{PV}=T i+(\mathrm{TAS} \div \beta)$

$\mathrm{PV}=1 \mathrm{~h} 30 \mathrm{~min}+($ TAS $[$ entre 4,45 a $5,39 \mathrm{dg} / \mathrm{L}] \div$ $1,5 \mathrm{dg} / \mathrm{L})$

$\mathrm{PV}=1 \mathrm{~h} 30 \mathrm{~min}+(3$ horas a $3 \mathrm{~h} 36 \mathrm{~min})$

Período de Vedação $=4 \mathrm{~h} 30 \mathrm{~min}$ a 5h06min.

Com a devida vênia para promover o batismo (em singela homenagem àquela que motivou o presente estudo): $\mathrm{PV}=T i+(\mathrm{TAS} \div \beta)$, eis a Fórmula DIGADI de

\footnotetext{
(23) Os cálculos levaram em consideração: (i) TAS de 4,45 $\div 1,5=2,96$, ou seja, aproximadamente 03 horas; e (ii) TAS de 5,39 $\div 1,5=3,59$. Assim, e considerando que 1 hora $=60$ minutos, de modo que 59/100 $=\mathrm{X} / 60$, então $\mathrm{X}=35,4$ minutos. O período de vedação em relação à TAS de 5,39 é de $3 \mathrm{~h} 36 \mathrm{~min}$.

(24) " $\mathrm{Co}$ is the point on the line where it intersects the ordinate. Thus, it represents the theoretical concentration that would have appeared in the blood if the entire dose of substance had been in diffusive equilibrium in the organism without previous conversion" (p.48).

${ }^{(25)}$ Bandeira de Mello ${ }^{31}$ sugere que os princípios jurídicos apresentam duas finalidades essenciais: estruturar o sistema legal e orientar a interpretação das normas.

${ }^{(26)}$ CTB. Art. $1^{\circ}, \S 2^{\circ}$ : "O trânsito, em condições seguras, é um direito de todos e dever dos órgãos e entidades componentes do Sistema Nacional de Trânsito, a estes cabendo, no âmbito das respectivas competências, adotar as medidas destinadas a assegurar esse direito.”
} 
Desintoxicação para o Trânsito Seguro.

Desse modo, pode-se responder afirmativamente ao questionamento promovido por minha mãe (e registrado na Introdução), pois, entre o término da fase de ingestão (logo após o jantar de sábado) e a manhã do dia seguinte, decorreu período muito superior a 5h06min, sendo suficiente para a conclusão das quatro fases da intoxicação etílica e superar o período de vedação (acima indicado).

Hoje, com o fundamento nos estudos realizados por Widmark ${ }^{2}$, Simonin ${ }^{3}$, Arbenz ${ }^{4}$, França ${ }^{5}$ e Sadler 6 , pode-se afirmar que os dois cálices de vinho ingeridos durante o jantar já estarão oxidados e eliminados pelo organismo na manhã do dia seguinte, de modo que minha mãe poderá assumir a direção de veículo automotor $\mathrm{e}$ dirigir com segurança, pois superou o período de vedação e sua TAS encontra-se em zero.

\section{APLICABILIDADE DOS CÁlCULOS PARA A REALIZAÇÃO DO TRÂNSITO SEGURO}

A Fórmula DIGADI (acima demonstrada) possui uma finalidade específica, voltada a estabelecer o período de vedação daquele que ingeriu bebida alcoólica e, após a fase de desintoxicação, pretende assumir a direção de veículo automotor.

Há, ainda, a possibilidade de o fator $\beta$ de conversão ser aplicado para determinar a taxa de álcool no sangue (TAS) no momento em que o infrator conduzia o veículo em via terrestre, e não apenas no momento da fiscalização ou da coleta da amostra. Essa estimativa, atualizando a alcoolemia ao tempo do fato, é identificada por Sadler ${ }^{6}$ como "cálculo retroativo" ou "estimativa retroativa".

$\mathrm{Na}$ esfera do Direito Criminal, seria muito interessante poder determinar a TAS no momento em que o condutor assumiu a direção do veículo, e não apenas quando foi submetido à fiscalização pela autoridade de trânsito (ou seus agentes) ou, ainda, no momento da coleta da amostra. Assim, para cada hora consumida com fiscalização, transporte do suspeito e coleta da amostra deveriam ser adicionados à TAS (indicada no laudo ou exame) uma unidade do fator $\beta$ de conversão, ou seja, $1,5 \mathrm{dg} / \mathrm{L}$ por hora.

Para promover o "cálculo retroativo" e estimar essa diferença, basta acrescentar o índice $0,15 \mathrm{dg} / \mathrm{L}$, por hora, ao resultado do teste/exame. Assim, TAS estimada $=$ resultado + (fator $\beta \times$ tempo em horas).

\section{EVITAR OS RISCOS DA EMBRIAGUEZ AO VOLANTE}

O Glossário de Álcool e Drogas, desenvolvido pela $\mathrm{OMS}^{32}$ remete o conceito de embriaguez ao verbete intoxicação, em que se destacam as expressões perturbação, substância psicoativa e álcool. A Embriaguez ao Volante, portanto, consiste na falta de aptidão para conduzir veículo ${ }^{8}$ em via terrestre, com a segurança necessária e exigida de todos aqueles que participam do fenômeno trânsito. Por isso, cada cidadão precisa conhecer os efeitos que as bebidas alcoólicas exercem sobre o organismo humano e o grave risco que representam à Segurança Viária.

Conhecendo e aplicando a fórmula de Desintoxicação para o Trânsito Seguro [PV=Ti+(TAS $\div \beta)]$, aquele que ingeriu bebida alcoólica poderá determinar o próprio período de vedação e cumprir seu dever como corresponsável pela segurança no trânsito. Para que nenhuma dúvida exista em relação a esse dever cívico, tanto nossa Constituição como o art. 32 da Convenção Americana de Direitos Humanos (conhecida como Pacto de São José da Costa Rica, de 1969) estabelecem uma "Correlação entre deveres e direitos" que "1. Toda pessoa tem deveres para com a família, a comunidade e a humanidade; 2 . Os direitos de cada pessoa são limitados pelos direitos dos demais, pela segurança de todos e pelas justas exigências do bem comum, em uma sociedade democrática" (p.442).

Para fortalecer a observância do dever cívico, a legislação pátria estabelece sanções administrativas (art. 165 e 277, $\S 3^{\circ}$, da Lei de Trânsito) e criminais (art. 306, do $\mathrm{CTB}$ ) àquele que conduzir veículo com excesso de alcoolemia ou sob a influência de substância psicoativa.

Cumpre a cada cidadão brasileiro (e aos estrangeiros que estejam participando do fenômeno trânsito em território nacional) o dever de zelar pela Segurança Viária e evitar situações que agravem o risco de mortes e lesões no trânsito. Caso venha a ingerir bebida alcoólica, deverá conhecer e observar o período de vedação, para somente então assumir a direção de veículo automotor com TAS em zero.

\section{SEGURANÇA VIÁRIA: GARANTIA CONSTITUCIONAL E RESPONSABILIDADE DE TODOS}

O conhecimento do tema e a complexa viagem do álcool por todo o organismo humano precisam integrar os programas de Educação para o Trânsito, de modo a permitir que os participantes do fenômeno trânsito conheçam o período de vedação durante o qual não poderão assumir a direção de veículo automotor, sob pena de ainda encontrarem-se sob a influência do álcool e gerarem grave risco à segurança viária.

O grande paradoxo da Embriaguez ao Volante ${ }^{6}$ precisa ser conhecido e respeitado, pois a mesma bebida que confere sensação de bem-estar, proporcionando 
a ilusão do estado perfeito(27), na realidade atua como depressor das funções cerebrais, reduzindo a coordenação motora, a capacidade de avaliação de riscos e o tempo de reação. Não é por outra razão que a OMS identificou a embriaguez ao volante como um dos cinco maiores fatores de risco à segurança viária ${ }^{23}$. Divulgar essas informações e implementar uma política de educação para a segurança do trânsito constitui dever imposto em nível constitucional ${ }^{(28)}$ a todos os entes da federação.

O dever de o Estado promover ações visando proporcionar segurança aos participantes do fenômeno trânsito é afirmado há décadas pela doutrina ${ }^{34}$. Hoje, o volume de mortes nas vias terrestres (tanto no território nacional como em todo o mundo) não permite dúvida em relação à seriedade do tema e a importância que todos, como participantes diuturnos do fenômeno trânsito, compreendam o grau de responsabilidade em relação à efetivação do trânsito em condições seguras.

A Segurança Viária constitui direito fundamental de segunda dimensão, ou seja, instrumento de proteção à vida e à incolumidade física de todos (pedestres, condutores de veículos ou de animais). É, sim, um direito social (descrito no art. $6^{\circ}$ da Constituição sob a forma de segurança que, sendo projetada sobre as vias terrestres, torna-se Segurança Viária) e dever do Estado, que deve proporcionar todos os meios necessários à realização do Trânsito Seguro.

O fenômeno trânsito, portanto, encontra-se distante da noção de direito individual, e precisa ser compreendido como um conjunto de deveres coletivos, pois, como bem afirmado pela Constituição da República de 1988 (art. 144), a segurança pública (que na esfera do fenômeno trânsito passa a ser denominada Segurança Viária) constitui dever do Estado, bem como direito e responsabilidade de todos.

No cumprimento dessa responsabilidade, compete a cada cidadão conhecer e cumprir as normas de circulação e de segurança no trânsito. Para tanto, "se beber, não dirija!"

Aquele, no entanto, que houver ingerido bebida alcoólica $^{(29)}$ e não desejar assumir os riscos de dirigir sob a influência de álcool deverá conhecer as fases de intoxicação alcoólica, aplicar a Fórmula DIGADI de Desintoxicação para o Trânsito Seguro e determinar o período de vedação a ser observado, antes de assumir a direção de veículo automotor.

Para que a Nação Brasileira não presencie $O$ Triunfo de Baco (com todo o respeito ao grande Mestre Velázquez) ${ }^{(30)}$ tampouco se torne vítima da maldição da uva $^{(31)}$, faz-se necessário agregar ao dito popular (se beber, não dirija!) o dever cívico e jurídico de respeitar o período de vedação e somente assumir a direção de veículo automotor, caso tenha ingerido bebida alcoólica, com a certeza que o organismo concluiu a fase de desintoxicação etílica e que a Taxa de Álcool no Sangue encontra-se em zero (TAS $=0$ ).

Honorato CM. Alcohol oxidation: if I have drunk, when will it be safe to drive? Saúde, Ética \& Justiça. 2013;18(1):88-102.

\begin{abstract}
Highway Safety not only involves Human Rights but also, and mainly, the duty of all the participants in road traffic. Each citizen, as a member of the phenomenon of traffic and co-responsible for the safety of others, needs to know the effects that alcohol can cause on the human body and must respect the restrictive period that has been stipulated for everyone who has drunk and, after the alcoholic detoxification phase, intends to drive a motor vehicle without violating safety rules and in compliance with Road Safety, knowing that the blood alcohol content BAC is zero. This paper has sought to establish the time necessary, for a person who has ingested a determined quantity of an alcoholic drink, to undergo ethyl-oxidation so that only afterwards, she/he can safely drive a vehicle on the highway.
\end{abstract}

KEYWORDS: Human rights; Alchohol drinking/legislation \& jurisprudence; Alcoholic beverages/toxicity; Alcoholic intoxication/complications; Automobile driving/legislation \& jurisprudence; Accidents, traffic/prevention \& control.

\footnotetext{
${ }^{(27)} \mathrm{O}$ tema "Ilusão do estado perfeito com álcool" foi desenvolvido por Rozestraten apud"

(28) Constituição da República Federativa do Brasil, de 1988. "Art. 23. É competência comum da União, dos Estados, do Distrito Federal e dos Municípios: [...]; XII - estabelecer e implantar política de educação para a segurança do trânsito".

(29) Pesquisa realizada em parceria entre a SENAD e UFGRS revelou que "uma proporção significativa e não diferenciada por tipo de motorista faz consumo de bebidas alcoólicas (ao redor de 22\%, no geral), e em seus dias normais de consumo consomem quantidades significativas de álcool $[\ldots]^{\prime \prime} \operatorname{apud}^{35}(\mathrm{p} .61)$

${ }^{\left({ }^{0}\right)}$ A expressão O Triunfo de Baco refere-se, respeitosamente, à obra "Los Borrachos", também conhecida como "El Triunfo de Baco", realizada pelo mestre Diego Velázquez, nos anos de 1628-1629 (óleo sobre tela), pertence ao acervo do Museu Nacional do Prado, em Madrid ${ }^{36}$.

(31) "Morrer quando bêbado: a vingança da uva"18 (p.179).
} 


\section{REFERÊNCIAS}

1. Albrecht PA. Criminologia: uma fundamentação para o direito penal. Rio de Janeiro: Lumen Juris; 2010.

2. Widmark EMP. Principle and applications of medicolegal alcohol determination. California (USA): Biomedical Publications; 1981.

3. Simonin C. Medicina legal judicial. Barcelona: Editorial JIMS; 1962.

4. Arbenz GO. Compêndio de medicina legal. Rio de Janeiro: Atheneu; 1983.

5. França GV. Medicina legal. 7a ed. Rio de Janeiro: Guanabara Koogan; 2004.

6. Sadler DW. Alcohol \& alcoholism. Dundee (Scotland): Department of Forensic Medicine; 2007 [cited 2012 May 10]. Available from: http://www.dundee.ac.uk/ forensicmedicine/notes/alcohol.pdf

7. Honorato CM. O Trânsito em condições seguras. Campinas (SP): Millennium; 2009

8. Castillo FT, Domínguez JAC; Uclés FM. Manual de seguridad vial: el factor alcohol. Navarra (España): Editorial Aranzadi; 2009.

9. Más español - libro dos. Rio de Janeiro: CCLS Publishing House; 1999.

10. Señas: diccionario para la enseñanza de la lengua española para brasileños. 3a ed. São Paulo: Martins Fontes; 2010. Tapa; p. 1208

11. Hoffmann MH, Cruz RM, Alchieri, JC, organizadores. Comportamento humano no trânsito. 2a ed. São Paulo: Casa do Psicólogo; 2007.

12. Nações Unidas. Resolução $\mathrm{n}^{\circ} \mathrm{A} / \mathrm{RES} / 58 / 289$, de 14 de abril de 2004 [citado 06 fev. 2013]. Disponível em: http:// www.who.int/violence injury prevention/media/news/en/ unga_58_289_en.pdf

13. Bianchi AS, organizador. Humanidade e trânsito: desafios para um futuro sustentável. In: Coletânea de conferências proferidas no VII Congresso Brasileiro de Psicologia do Trânsito e I Congresso Ibero-Americano de Psicologia do Trânsito e Transporte. 26 a 28 de novembro de 2007. Curitiba: Conselho Regional de Psicologia da $8^{\text {a Região; }}$ 2009

14. Almeida Júnior A, Costa Júnior JBO. Lições de medicina legal. 20a ed. São Paulo: Nacional; 1991.

15. Global status report on road safety: time for action. Geneva (Switzerland): World Health Organization, 2009 [cited 2012 Aug 08]. Available from: www.who.int/violence injury_prevention/road_safety_status/2009.

16. Andrade AG, Anthony JC, Silveira CM. Álcool e suas conseqüências: uma abordagem multiconceitual. Barueri: Minha Editora; 2009 [citado 08 maio 2012]. Disponível em: http://www.cisa.org.br/categoria.html?FhIdTexto=1f8 baab995757f67ef9596f097e8d2b6

17. Rozestraten RJA. Psicologia do trânsito: conceitos e processos básicos. São Paulo: EPU - Editora da Universidade de São Paulo; 1988.

18. Wilde GJS. O limite aceitável de risco: uma nova psicologia de segurança e de saúde: o que funciona? O que não funciona? E por que? São Paulo: Casa do Psicólogo; 2005.

19. Lazzari CF, Witter IRR. Nova coletânea de legislação de trânsito. 14a ed. Porto Alegre: Sagra Luzzatto; 1997.

20. Honorato CM. Trânsito: infrações e crimes. Campinas: Millennium; 2000.

21. Honorato CM. Dois crimes de embriaguez ao volante e as alterações introduzidas pela Lei 11.705/2008. Rev Tribunais. 2009;880:341-74. Disponível em: http://www. ceaf.mppr.mp.br/arquivos/File/Ingresso_e_Vitaliciamento/ Texto1_DrCassio1.pdf

22. Nações Unidas. Res. $n^{\circ} \mathrm{A} / 64 / 255$. Melhoria da segurança viária no mundo [acesso em 06 fev 2013]. Disponível em http://www.who.int/violence_injury_prevention/ publications/road_traffic/UN_GA_resolution-54-255-en. pdf

23. Nações Unidas. Res. $n^{\circ} \mathrm{A} / 60 / 181$. Informe Mundial sobre Prevenção de Traumatismos Causados pelo Trânsito [citado em 06 fev. 2013]. Disponível em: http://www.unece.org/ fileadmin/DAM/trans/roadsafe/docs/A-60-181s.pdf

24. Honorato CM. Trânsito seguro: direito fundamental de segunda dimensão. Rev Tribunais. 2011;911:10769. Disponível em: http://www.stf.jus.br/arquivo/ $\mathrm{cms} /$ processoAudienciaPublicaAdin4103/anexo/ TRANSITO SEGURO Direito Fundamental CASSIO HONORATO_Texto_impresso_RT_911_em_Set_2011. pdf

25. UNICAMP. Viva Mais. Programa de prevenção ao uso de substâncias psicoativas lícitas e ilícitas [citado 31 ago. 2012]. Disponível em: http://www.prdu.unicamp.br/ vivamais/dependencia_alcool.html

26. Feltre R. Química - química geral. 4a ed. São Paulo: Moderna; 1994

27. Feltre R. Química - físico-química. 4a ed. São Paulo: Moderna; 1994

28. Ferreira $\mathrm{ABH}$. Dicionário da língua portuguesa. Rio de Janeiro: Nova Fronteira; 1985. Cinética; p.328.

29. Dubowski KM. Absorption, distribution and elimination of alcohol: highway safety aspects. J Stud Alcohol Suppl. 1985;10:98-108. Available from: http://www.jsad.com/ jsad/article/Absorption_Distribution_and_Elimination_of Alcohol_Highway_Safety_Aspects/2478.html

30. Ramchandani VA, Bosron WF, Li TK. Research advances in ethanol metabolism. Pathol Biol (Paris). 2001;49(9):67682. DOI: http://dx.doi.org/10.1016/S0369-8114(01)00232-

31. Bandeira de Mello CA. Elementos de direito administrativo. 2a ed. São Paulo: RT; 1991.

32. Bertolote JM. Glossário de álcool e drogas. Brasília: 
Honorato CM. Etiloxidação: se bebi, quando poderei dirigir com segurança?

Secretaria Nacional Antidrogas (SENAD); 2006. Disponível em: http:/www.obid.senad.gov.br/portais/ OBID/biblioteca/documentos/Publicacoes/327615.pdf

33. Piovesan F. Direitos humanos e o direito constitucional internacional. 6a ed. São Paulo: Max Limonad; 2004.

34. Faria B. Das contravenções penais. Rio de Janeiro: Record; 1958.

Recebido em: 23/03/2013

Aprovado em: 23/05/2013
35. Pechansky F, Duarte PCAV, De Boni RB, organizadores. Uso de bebidas alcoólicas e outras drogas nas rodovias brasileiras e outros estudos. Porto Alegre: Secretaria Nacional de Políticas sobre Drogas (SENAD); 2010.

36. España. Ministerio de Cultura. O guia do prado (Edição Portuguesa). 2a ed. Madrid: Museo Nacional del Prado; 2011. 